\title{
Precision, Honesty and Liveliness: The Newspaper Medium in The Unfortunates by B. S. Johnson
}

\begin{abstract}
The article analyses the representation of the newspaper medium in The Unfortunates - the fourth novel by the post-war British avant-garde author, B. S. Johnson. The narrator's job as a football reporter is discussed with reference to other themes and the unconventional form of the novel. Special attention is paid to the section called "The pitch worn", which presents the process of writing the report. The aim is to see how the chapter resonates within the whole work and what it reveals as regards Johnson's views on precision, honesty, liveliness and the author-reader relationship. Literary analysis is accompanied by references to journalism and media studies.

Keywords: B. S. Johnson, The Unfortunates, newspaper medium, journalism, precision, liveliness
\end{abstract}

\section{Introduction}

A discussion on intersections between narrative and media, which this special issue aims at stimulating, may, I hope, benefit from a reflection on B. S. Johnson - a British post-war avant-garde author, who worked across different arts. Aware of the influence media have on one another, he saw literature along a broader cultural landscape and, as Hucklesby (2014) notes, knew "that the future of print fiction hinges on its relationship with other media" (p. 204). Though probably most commonly associated with his novels, republished in the 2010s by Picador, Johnson worked also as a journalist, wrote theatre plays (six of which were published in the collection Well Done, God! in 2013) and directed films (released by the British Film Institute in the same year).

The growing interest in his works in the current century has brought numerous interpretations of his fourth novel, The Unfortunates, which, thanks to its unconventional shape, has been viewed as "the most extreme" by the author himself (Johnson, 1973, p. 20) and, subsequently, also by reviewers and researchers ${ }^{1}$. First published in 1969, it comes in the shape of a book-in-a-box containing 27 separate sections. Two of them are marked as "First" and "Last" while the remaining ones

See e.g., Jordan (2014) and Drąg (2017).

Katarzyna Biela, Instytut Filologii Angielskiej, Uniwersytet Jagielloński, ul. Gołębia 24, 31-007 Kraków, k.biela@doctoral.uj.edu.pl, ORCID: 0000-0002-7392-2546 
are left to be read in a random order. The story presents the narrator as he arrives in Nottingham to write a football report and realizes that he used to visit the city to see his friend, Tony, who died of cancer at the age of 29.

Jordan (2010), for instance, analyses the novel with reference to the category of chance and aleatory writing in Chance and the Modern British Novel: From Henry Green to Iris Murdoch. Lea (2015), in turn, focuses on the theme of illness and cancer in "Narrative Wreckage: Cancer and the Unfortunate Body in B. S. Johnson" while Drąg (2017) highlights the motif of friendship in "In Pieces: Fragmentation, Friendship, and Mourning in B. S. Johnson's The Unfortunates". The unconventional shape of the book has also been of interest, among others, for White (2005) in Reading the Graphic Surface (2005) and Bazarnik in Liberature: A Book-bound Genre (2016).

Thinking about intersections between narrative and other media, I would like to draw on yet another theme in the novel, that is news reporting. The importance of the motif is suggested by the narrator's job - the football report he is supposed to write is what brings him to the city, and the match is the fixed event he has in mind while strolling around, observing and recollecting the past in the order determined by the unplanned walk (and the reader). The intersection between the novel and news writing is also strengthened by the biographical context - Johnson played and watched football, went to see matches with his father, at some point even applied to join the Chelsea team and later worked as a reporter, which all must have earned him a broad knowledge in the field (Johnson, 2013, pp. 407-411).

Still, presumably due to the parallel significance of other themes in The Unfortunates, such as e.g. death and trauma, the representation of the newspaper medium and journalism seems to be a frame rather than a subject in the story. The narrator himself, though he does not forget about the match, focuses on the lost friendship as well as his mental state and unwillingly turns to the job he does out of necessity rather than out of preference. Finding this ambiguity quite interesting, I would like to take a closer look at the narrator's job and the report he writes, mainly in the section "The pitch worn", which is actually the longest out of the 27. Commenting on the novel, Johnson's friend, Zulfikar Ghose (2015), wrote that he sees this as a fortunate coincidence if this section is read as the second last for it appears to fuse all themes relevant to The Unfortunates:

Incidentally, it occurs to me that the football reporting section gains by coming second last; for by then one already knows so much about what you've been suffering in the town, and one is moved by the fact that you're having to watch a mediocre match and write about it and then sending the copy while your mind is full of other things (as cit. in Guignery, 2015, p. 268).

Taking this as a suggestion that the chapter might be an important micro-story within a larger whole, my aim is to see how it resonates in the novel and what characteristics of Johnson's writing it reveals, especially as regards his devotion 
to truth, precision and honesty. Subsequently, it is worth looking at the news reporting theme through the lens of contemporary journalism and investigate what it may tell about Johnson's approach to the author-reader relationship.

\section{Truth in journalism and in B. S. Johnson's view}

Two complementary conceptualisations of journalism found their way into media studies as presented by Bird and Dardenne (1987), as well as by Carey (1989): one focuses on the transfer of information and the search for truth while the other highlights the continuity of communication, as well as the mission to create a coherent picture of reality and to bring together the audience as a community living in particular circumstances. Bird and Dardenne (1987) analyse news as a narrative, assuming it is beneficial to view journalism not only in terms of its informative function, but also with regard to its symbolic and cultural value. As they contend, their aim is not to "negate the value of considering news as corresponding with outside reality, as affecting or being affected by society, as a product of journalists or of bureaucratic organization", but to "introduce another dimension to news, one in which the stories of news transcend their traditional functions of informing and explaining" (p. 69). Using myth as a theoretical framework, they treat it as a means of comprehending troubling phenomena, yet not necessarily by reflecting the world, but rather by constructing an autonomous representation of reality (p. 70). In their opinion, releasing news similarly helps to understand what is happening, for it also "is a way in which people create order out of disorder, transforming knowing into telling" (p. 70). Relying on "the authority as 'truth", both myth and news distinguish, for example, between what can and what cannot be accepted (pp. 71, 80). From such a perspective, crime reports not only provide information about the people involved and further possible danger, but primarily outline normative guidelines as for what kind of behaviour leads to arrest (p. 71).

Carey (1989), in turn, comments on journalism in a broader context while he distinguishes two approaches to communication: a transmission view and a ritual view. The former presents "the medium as an instrument for disseminating news and knowledge", while also asking what kind of effect this has on the audience: whether they gain knowledge or become more confused, whether they are willing to change their habits, whether they believe what they read about or begin to doubt (p. 20). The latter approach seems to suggest that journalism stimulates action in a given socio-cultural context and that it situates readers within this context:

The model here is not that of information acquisition, though such acquisition occurs, but of dramatic action in which a reader joins the world of contending forces as an observer at a play. We do not encounter questions about the effect or functions of messages as such, but the role of presentation and involvement in the structuring of the reader's life and time (p. 21). 
Thus, news can be treated as a linear story or a series of stories complemented each day by new information, but also as a means of communication that plays a role in building the picture of reality.

The questions of knowledge and understanding reality were especially important for journalism in the 1960s, 70s and $80 \mathrm{~s}^{2}$, which, as Bird and Dardenne (1987) note, "saw an increase in critiques of positivism and increased doubts about the possibility of reaching truth through empirical description" (p. 205). A trace of such an attitude can be found in B. S. Johnson's "Introduction" to his collection of short prose Aren't You Rather Young to Be Writing Your Memoirs? Though he does not comment directly on journalism, but rather theorizes on literature, he is clearly interested in the complexity of the transforming reality and the attempts to obtain stability. Published in 1973, the "Introduction" features a reflection that

[p]resent-day reality is markedly different from say nineteenth-century reality. Then it was possible to believe in pattern and eternity, but today what characterises our reality is the probability that chaos is the most likely explanation ; while at the same time recognizing that even to seek an explanation represents a denial of chaos [punctuation original] (Johnson, 1973, p. 17).

Hence, the task Johnson accepts as a novelist touches upon a paradox of a futile quest - a search for what might not be possible to achieve. He is of the opinion that writers should accompany philosophers in facing contradictions and he admits that he keeps acting as if there was a certain pattern beyond the complicated reality (p. 18). He is also very much devoted to truth, which he chooses as one of his major writing goals. As he states, "I am not interested in telling lies in my own novels" (p. 14). A corresponding tension between the known and the unknown is reflected in The Unfortunates, where two sections are marked as the first and the last while the rest remain reshufflable, demonstrating that "control and order are anticipated and yet frustrated" (Tew, 2002, p. 40). It seems that Johnson was willing to accept a certain amount of precarity in the search for innovation and new knowledge, wishing other writers and readers would join him and embrace works that go against literary tradition (Johnson, 1973, p. 29-31).

\section{Precision}

The appreciation of truth and the willingness to search appear to be the issues connecting Johnson with journalism, which prompts to have a closer look at the

2 Correspondingly, Ward (2018) speaks of a shift from realist to social constructivist epistemologies in the mid $20^{\text {th }}$ century, suggesting that people began to view knowledge as no longer objective, but constructed by humanity (p. 63). He also treats the 60s as the end of the Epistemology of News Objectivity era and the beginning of the Alternate Epistemologies era (p. 68). 
depiction of the football report the narrator in The Unfortunates is supposed to write. In fact, the article is reprinted in the novel three times in three different shapes. Firstly, as the narrator is composing the report in the "The pitch worn" section, where his notes in italics are interwoven with his internal monologue in straight font, e.g., "Alexander, dragging his slow length along from right back, hit a long one which beat Phipps but struck the intersection [emphasis original], like a wounded snake has to be worked in somewhere, no, it'll never work, too contrived, scrub it" (Johnson, 1999, p. 6) ${ }^{3}$. This carries on for nine pages, until a blank leading into a new paragraph illustrates that he is putting the notes together and editing the text, so that it can be published quickly: Now I must hack this into some shape, now I must make it into 500 well-chosen words [...] Get on.

By five. In 40 minutes" [spacing original] (p. 9). Later, the narrator is found repeating the freshly written article over the telephone. The loose phrases are separated by numerous blanks illustrating how he is waiting for them to be registered in the newspaper office. Yet another characteristic feature of this part is that the narrator is reading out loud all punctuation marks and indicating verbally how he imagines the text to be distributed in print. This is further complemented by additional comments addressed to the receiver, e.g., "over the bar from no more than three yards out full point new par Okay, I'll wait" [spacing original] (p. 10). Finally, the report in its printed shape is reproduced on the internal back cover of the box containing the 27 sections. Here, the newspaper convention is shown in the way that the article has a headline, a subtitle and appears in two narrow columns. In this way, the readers are presented with the whole creative process from note-taking to the final published product, which seems to demonstrate both the desire for an accurate description of the events and the willingness to show how the account has developed - that its original shape is the outcome of changes and transmissions.

The pursuit of precision visible in such a thorough depiction of writing the report is worth noting as it is an attitude journalists are expected to adopt. Taking into account "the authority as "truth"” (Bird \& Dardenne, 1987, p. 80), as well as their readers, reporters should be as accurate as possible, honest when they are aware that some details are unknown and caring about providing fresh information in an attractive way. As Randall (2007) contends, "[j]ournalism should be the enemy of imprecision" (p. 164). Outlining his advice for amateur reporters, he stresses how important it is to know what one wants to say and to keep searching for a proper way to get it across: "Think hard about the real nature of what it is that you are trying to convey and try to find a phrase that fits the bill perfectly"

3 I am using the reprint edition of The Unfortunates published by Picador in 1999. All subsequent references will be to this edition and they will include an opening phrase of a given section along with a page number. 
(p. 160). Similarly, Reeves and Keeble (2015) explain that a reporter should try not to overuse words and stay reserved towards elaborate constructions in order to keep his account short and simple: "Complex sentences overload with long subordinate clauses should be avoided. Use short, precise sentences" (p. 119).

Throughout his career, Johnson paid great attention to the meaning-making process and cared about the ways in which he could convey different senses. As he states in the "Introduction", "I want my ideas to be expressed so precisely that the very minimum of room for interpretation is left" (Johnson, 1973, p. 28). This may correspond to the representation of the reporting process in The Unfortunates, but also to the manner in which the narrator describes his walk around the city before the match as well as his relationship with Tony. Aiming at accuracy, he provides numerous details. For instance, in his observations concerning the weather, he would keep redefining the kind of rain and resort to his physical and mental reactions in order to render the moment thoroughly and precisely: "It begins to rain, rain like an extension of the air, wet air, not falling as drops, in material terms, that is, in drops one would call drops, but a fine air mist of wetness, of rain, that makes me blink, that just depresses me one stage further..." (Johnson, 1999, "Time! " [spacing original], p. 3). Also, the descriptions of Tony's deterioration include biological details and the narrator's commentary on his mental processing, e.g., "And his teeth, I never remember seeing Tony's teeth before, they were there, of course, in that fleshy mouth, but now the mouth was not fleshy, the flesh was gone, not gone, but tautened, disfigured..." ("So he came to his parents...", p. 2).

Still, though precise, the narrative strategy is complex and ambiguous. The consideration of both the outside world and the subjective impressions make the account broad and detailed, yet at the same time objectivity is subverted. Parallel to how the narrator presents the entire process of reporting the football match, outlining how the text is being composed in his mind, he adds his own perspective also to the account of the present and past events outside the game. Precision in this sense means providing different perspectives and revealing one's own reactions. The reformulations and details seem to go against the model of reporting as based on brevity as they suggest an intense flow of words.

\section{Honesty}

Furthermore, accuracy is achieved through honesty and the awareness that not everything can be mediated or expressed. The blanks used throughout the novel indicate silence and waiting, like in the example of reading the report over the telephone, but sometimes they also stand for lapses of memory, e.g.,

But when could that have been? Which day? Was it before I was ill? Yes, or June would not have expected much of me, though it was not much to expect, in any case, no, from me. I cannot place this, though, it will not fall into place ("The estate. " " [spacing original], p. 8). 
Apart from that, the blanks are used to show resignation and existential doubts, e.g.,

when there were race-riots in the city, he was interviewed by reporters, or something, I don't remember, why should I, it doesn't matter, nothing does, it's all chaos, look at his death, why? Why not? [spacing original] ("His dog, or his parents' dog", p. 3).

Thus, the accuracy achieved through details is accompanied by the descriptions of moments when the opposite is at stake, that is when the narrator feels lost for words due to memory failure or negative mood. Demonstrating "a passing away of the power of language" in the novel (Tew, 2002, p. 35) seems to chime with the journalistic awareness that

[t]here are aspects of the process of journalism which often compromise truth. The lack of time to collate a totally comprehensive account, the lack of access to all the sources and information and the need to write the story to a finite, often quite short length (Randall, 2007, p. 161).

Randall explains that these are all acceptable on the condition that the reporter knows his account is not absolute (p. 161). He also admits that an even better strategy is to look for ways to confront these kind of obstacles (p. 161). The abovequoted passages, thematically perhaps especially the one where the reference to interviewing is juxtaposed with the narrator's hesitation, illustrate that the narrator in The Unfortunates bears in mind the inevitable limitations of reporting, facing them with sincerity and, if necessary, silence. The account is not entirely composed of neat sentences, but the narrator decides to pause at times, which is in contrast to the flow of words in other passages.

Thus, his way of communicating appears to draw on the transmission view, as described by Carey (1989), for he provides information and cares about accuracy. Subsequently, though, this seems to lead him towards the ritual view and the acknowledgement that storytelling is a process of structuring a representation of reality, composed of different stages, reformulations and breaks. The same applies to the unconventional form of the novel, which lets Johnson convey "as accurately as possible what happened" and at the same time construct "a physical tangible metaphor for randomness" (Johnson, 1973, pp. 25-26).

\section{Liveliness}

Yet another pair of key issues in journalism, which may be useful in the analysis of The Unfortunates, is freshness and liveliness. In Randall's (2007) opinion, providing readers with new information, but also taking care of the writing style in terms of avoiding clichés and automatic collocations is crucial to professional reporting: "The whole point of articles in newspapers is to give readers something they have not had before" (p. 158). Furthermore, journalists should keep an 
appropriate pace in their text, so as to make the account testify to the atmosphere during the event. It is beneficial to prioritize active verbs over the passive voice, to construct economical sentences and not to overuse adjectives (p. 171).

The narrator in The Unfortunates also tries to avoid conventional phrasing from the very beginning of the match: "City's goal had a narrow escape alter that, cliché, cross it through, later" ("The pitch worn", p. 2). From this perspective a reason for giving readers access to three different versions of the football report might be to provide them with a live account of the writing process, especially when at the beginning of the "The pitch worn" section the narrator fuses writing with thinking. The blanks in this context also guarantee freshness as they let the narrative start again numerous times, point to the change of topic as well as offer the narrator a chance to rephrase a structure and present it in a new way. On a larger scale, a similar effect is achieved by the loose sections, which let themselves be arranged in a new order in each reading.

What might also be of significance is that the narrator disapproves of the editors who expect him to follow their guidelines and correct his reports, so that the texts suit the newspaper better. For instance, his view on puns is unconventional for he would not eliminate them: "and yet in one way it was, his lucky day: Holman, hunting yes! round for a way through [italics original] that's the sort of horrible pun they hate, I enjoy" ("The pitch worn", p. 3). He is actually right about the journalistic standards in this reflection. The value of puns is questionable in news writing because they are rarely new. As Randall (2007) advises, "An outright ban would be a bit severe, because once in a while (say every three years) somewhere in the world a journalist comes up with a good fresh one. Meanwhile, many millions more that are anything but fresh get published" (p. 159). The narrator's distance towards the convention may suggest that he would like to preserve his personal writing style, even if it is not necessarily innovative throughout. Perhaps for him freshness stems from directness and authenticity, which are shattered by the editorial corrections intruding into his original text. This matches what Johnson himself thought about editing:

it was what appeared in print that was usually such a pain. I would take great trouble to try to make my copy as good a piece of writing as anything else I might do [...] and the sub-editors would almost invariably ruin it not only by cutting it, but also by re-writing to some faceless sub-standard of their own (Johnson, 2013, p. 410).

Moreover, the narrator is unhappy with the monotonous view that all matches should be reported as interesting: "Even if it's a bad match, they tell you, disguise it, write as though it were a good match. Bollocks to that, bollocks to this stinking match" ("The pitch worn", p. 5). Such disagreements are quite common in press industry as editors would often like stories to be shocking, so that they more easily attract as many people as possible. Randall (2007) explains that "writers know 
what editors prize as a strong news story and in writing the story as strongly as they dare, they often make omissions and use language which exaggerates or 'hypes' the story beyond its true value" (p. 161). Bearing in mind Johnson's devotion to truth, it is no wonder that the narrator he employs disapproves of such a vision of storytelling. Bird and Dardenne (2009) are of the opinion that reporters should not only be aware of how editing can affect truth, but that their mission is to counteract, also because oftentimes a newspaper has a particular political or social profile inscribed into all articles: "journalists remain obligated to make the best possible effort to report and make sense of the world [...] not to simply serve their corporate masters, by telling the government story, but to tell the most truthful story or stories that best serve citizens" (p. 214). From this perspective, reporting can be treated as an instrument of opposition and conveying an alternative view on reality. Again, it is probably not surprising that such an issue is addressed in the novel by the author who was described by his biographer, Jonathan Coe (2005), as "Britain's one-man literary avant-garde of the 1960s" (p. 3).

The content of The Unfortunates is also meaningful in this context as the novel features different stories from the narrator's past and present, touching upon death, illness, friendship, love, football reporting and many other themes. Additionally, the shape of the novel physically demonstrates that each section can be read as an individual segment included in a whole that transforms in each reading. The reality in the novel is presented not as uniform and homogeneous, but rather as diverse, susceptible to change and requiring an up-to-date, live and genuine description. This suggests that, again, setting off from informativity and accuracy, Johnson is leaning towards the ritual view on communication. The variety of motifs, including the dialogue with newspaper conventions, as well as the resignation from the traditional linear writing prompt one to view The Unfortunates as a work aiming at "presentation and involvement" (Carey, 1989, p. 21).

\section{Conclusion}

In conclusion, it might be worth looking at The Unfortunates from the perspective of the recent decades. Although Johnson worked mainly in the 1960s, the contemporary context can highlight important features of his writing. As stated at the beginning, he is experiencing a revival of interest and so his novels are interpreted with reference to current phenomena. Hooper (2014, para. 9), for instance, contends that Johnson is a perfect fit into the age of technological advancements and notes that some of his ideas, such as cutting holes in his second novel, Albert Angelo, have been used and developed since the post-war period. As for Johnson's fourth novel, in Hooper's opinion, “the choose-yourown-adventure qualities of The Unfortunates would lend it perfectly to this era of digitised readers and shuffle settings" (para. 11). Indeed, the act of arranging the chapters emphasizes the reader's role in constructing the story. White (2005) 
remarks that analyzing the novel confronts the commentator with a doubt whether any of his readers will share his sequence of sections (p. 115). Likewise, Bazarnik (2010) views the form of The Unfortunates as a suggestion for the reader to play a part in the process of meaning-making: "While the narrator speaks through the text, the author-arranger performs a non-verbal gesture addressed to the reader-a gesture of invitation to engage in a dialogue with him and with his work" (p. 127). Johnson may thus presumably be seen as an anticipator of the digital age, electronic literature and the ongoing virtual conversation enabling users to make their personal statement in relation to the online content.

A similar transformation has affected journalism and writing the news ${ }^{4}$. As people were offered the opportunity to express their opinions on blogs and personal websites, the search for knowledge has begun to resemble an exchange of information rather than a one-way flow (Bird \& Dardenne, 2009, p. 212). Now, as a result, "news is part of a conversation" and the reporter's task is to lead his readership through the "cacophony of narratives" (Bird \& Dardenne, 2009, p. 212) rather than to speak from the position of someone who has access to the inaccessible. Meaning is not given, but being constructed by a community whose members participate in interpreting events and in the creation of a given vision of reality: "News reception is about process, not text, as 'the story' emerges in conversation with the news narrative as framing structure. In making sense of news, we involve others in the negotiation of meaning and its cultural significance emerges through everyday interaction" (Bird \& Dardenne, 2009, p. 212). Hence, the ritual view on communication as action within a socio-cultural context seems to be suitable for the contemporary times.

Whether Johnson could be seen as an anticipator of journalism nowadays cannot be so straightforwardly concluded, yet he was aware that news writing is a process featuring transformation and an interaction of influences. Otherwise, probably, he would not have presented all stages of creating the report and he would not have fossilized the printed version of the article on the box in contrast to the working versions which are among the shuffled sections. In this sense, the invitation for the readers to participate in the construction of the story is also a meaningful gesture. Simultaneously, Johnson was aware that a reporter is responsible for outlining a path for interpretation, which is demonstrated in his different strategies for achieving precision, such as providing details and admitting to the lack of knowledge.

Finally, closing the discussion on how the longest section resonates in the novel, the chapter perhaps deserves a juxtaposition with the shortest one, where the narrator states that Tony's wife, June, called him to inform about her husband's death. Though the white space below the only paragraph in the section most probably stands for grief, shock and silence, the fact that the painful part about the "fossilization" of

4 See also Ward (2018, pp. 63-82, especially 76-77), and Örnebring (2018, pp. 555-568). 
Tony's body takes up the least space in the novel might also suggest that the story is primarily about action and liveliness: about how Tony lived and how difficult it is for the narrator to live without him.

\section{Acknowledgements}

Research financed from the budget for science and arts 2018-2022 as a research project being a part of the "Diamond Grant" programme.

I would like to thank my supervisor, dr. hab. Katarzyna Bazarnik, for her support and the anonymous reviewers for their comments and suggestions.

\section{References}

Bazarnik, K. (2010). Chronotope in liberature. In K. Bazarnik, \& B. Kucała (Eds.), James Joyce and After: Writer and Time (pp. 117-132). Newcastle: Cambridge Scholars Publishing.

Bazarnik, K. (2016). Liberature: A Book-bound Genre. Kraków: Jagiellonian University Press. DOI: $10.4467 / \mathrm{K} 9565.31 / \mathrm{e} / 16.16 .5378$.

Bird, S. E., \& Dardenne. R. W. (1987). Myth, chronicle, and story: Exploring the narrative qualities of news. In J. W. Carey (Ed.), Media, Myths and Narratives: Television and the Press (pp. 67-86). Newbury Park: SAGE Publications.

Bird, S. E., \& Dardenne. R. W. (2009). Rethinking news and myth as storytelling. In K. WahlJorgensen, \& T. Hanitzsch (Eds.), The Handbook of Journalism Studies (pp. 205-217). New York and London: Routledge.

Carey, J. W. (1989). A Cultural Approach to Communication. In J. W. Carey (Ed.), Communication as Culture: Essays on Media and Society (pp. 13-36). Boston: Unwin Hyman.

Coe, J. (2005). Like a Fiery Elephant: The Story of B. S. Johnson. London: Picador.

Drąg, W. (2017). In Pieces: Fragmentation, Friendship, and Mourning in B. S. Johnson's "The Unfortunates". In E. Kowal, \& R. Kusek (Eds.), The Politics and Poetics of Friendship (pp. 309-322). Kraków: Jagiellonian University Press.

Guignery, V. (Ed.). (2015). The B. S. Johnson - Zulfikar Ghose Correspondence. Newcastle: Cambridge Scholars Publishing.

Hooper, M. (2014). Why BS Johnson suits the digital age. The Guardian. Retrieved January 28, 2020, from https://www.theguardian.com/books/.

Hucklesby, D. (2014). B.S. Johnson, Giles Gordon and a 'New Fiction': The book, the screen and the e-book. In J. Jordan, \& M. Ryle (Eds.), B. S. Johnson and Post-war Literature: Possibilities of the Avant Garde (pp. 202-216). Basingstoke: Palgrave Macmillan.

Johnson, B. S. (1973). Introduction. In B. S. Johnson, Aren't You Rather Young to Be Writing Your Memoirs? (pp. 11-31). London: Hutchinson.

Johnson, B. S. (1999). The Unfortunates. London: Picador.

Johnson, B. S. (2013). [On football]. In J. Coe, P. Tew, \& J. Jordan (Eds.), Well Done, God! (pp. 407-411). London: Picador.

Jordan, J. (2010). Chance and the Modern British Novel: From Henry Green to Iris Murdoch (2010). New York: Continuum International Publishing Group.

Jordan, J. (2014). 'For recuperation': elegy, form, and the aleatory in B. S. Johnson "The Unfortunates". Textual Practice, 28(5), pp. 745-761.

Lea, D. (2015). Narrative Wreckage: Cancer and the Unfortunate Body in B. S. Johnson. English Studies, 96(7), 785-798.

Örnebring, H. (2018). Journalism and Change. In T. P. Vos (Ed.), Journalism (pp. 555-568). Boston: De Gruyter. 
Randall, D. (2007). The Universal Journalist. $3^{\text {rd }}$ ed. London: Pluto Press.

Reeves, I., \& Keeble, R. L. (2015). The Newspapers Handbook. $5^{\text {th }}$ ed. London and New York: Routledge.

Tew, Ph. (2002). B. S. Johnson. Review Of Contemporary Fiction, Spring 22(1), 7-52.

Ward, S. J. A. (2018). Epistemologies of journalism. In T. P. Vos (Ed.), Journalism (pp. 63-82). Boston: De Gruyter.

White, G. (2005). Reading the Graphic Surface: The Presence of the Book in Prose Fiction. Manchester, New York: Manchester University Press. 